\title{
Strengthening the Connection Between Acquired Brain Injury (ABI) and Family Violence: The Importance of Ongoing Monitoring, Research and Inclusive Terminology
}

\author{
Gaye T. Lansdell ${ }^{1}$ (D) Bernadette J. Saunders ${ }^{2} \cdot$ Anna Eriksson $^{3} \cdot$ Rebecca Bunn $^{4}$
}

Accepted: 18 April 2021 / Published online: 8 May 2021

(c) The Author(s), under exclusive licence to Springer Science+Business Media, LLC, part of Springer Nature 2021

\begin{abstract}
Family violence (FV) harms communities worldwide so FV prevention strategies and effective responses are urgently needed. This article reports on FV apparent in a study which explored the experiences of people with both ABI and justice system encounters in Victoria, Australia. One hundred interviews and one focus group consulted people with ABI, their families and carers, and various stakeholder groups in the Victorian justice system in Australia. Qualitative content analysis determined dominant themes and sub-themes and the less common themes. Inductive interpretive content analysis identified themes commonly found in previous published research and themes that appeared unique to, or unanticipated in, our data, such as the FV theme upon which this article focuses. Our findings reveal that FV has adversely affected many people with ABI who came into contact with Victoria's justice system. Further, as ABI and FV often co-occur with substance abuse, mental health problems, socio-economic and many other significant disadvantages, for some FV perpetrators with an ABI, their $\mathrm{ABI}$ symptoms and characteristic co-morbidities may be a mitigating factor in their offending. The connection between $\mathrm{ABI}$ and family violence emerged as a troubling research theme. Indeed, the impact of FV on too many of our participants with an ABI compels us to call for further related research and secondary prevention programs targeted at FV victims, and offenders, living with ABI. An intersectional understanding of family violence and TBI/ABI in social ecological contexts is required to better understand brain injury at both individual and population levels.
\end{abstract}

Keywords Family violence $\cdot$ Interpersonal violence $\cdot$ Acquired brain injury $\cdot$ Disability $\cdot$ Neurodisability $\cdot$ Criminal justice system

Family violence is a serious, widespread issue with significant social and economic consequences (Zieman et al., 2017). While variably defined, in Australia, family violence refers to "violence between family members as well as between current and former intimate partners" which

Gaye T. Lansdell

gaye.lansdell@monash.edu

1 Faculty of Law, Monash University, Wellington Rd, Clayton, Melbourne, VIC 3800, Australia

2 Department of Social Work, Faculty of Medicine, Nursing and Health Sciences, Monash University, Caulfield East, VIC, Australia

3 Department of Social Sciences, Faculty of Arts, Monash University, Clayton, VIC, Australia

4 Ph.D Candidate, University of Melbourne, Melbourne, VIC, Australia may include "physical, sexual, emotional and psychological abuse" and controlling or threatening behaviour (AIHW, 2018 , p. 3). While both men and women commit family violence, and it can occur within any familial relationships and against children, the most common form of family violence is perpetrated by men against women who are their current or former partners (State of Victoria, 2016, p. 2). In other jurisdictions, such as the United States, the term "intimate partner violence" (IPV) is more commonly used, with the term "battering" also used to describe "a severe and escalating form of partner violence" (WHO, 2012, p. 1). There are a number of competing explanatory theories for family violence, including: sociological, feminist and ecological theories (Ali \& Naylor, 2013a), biological and psychological theories (Ali \& Naylor, 2013b; Pinto et al., 2010) and neuropsychological theories (Bueso-Izquierdo et al., 2015). In Australia, the prevailing view is that "the underlying drivers of [family violence] can reflect inequalities in the 
distribution of power, resources and opportunity between females and males" and are influenced by "cultural values", "social factors", "situational factors" and the "personal history" of victims and perpetrators (AIHW, 2018, p. 11).

Acquired brain injury (ABI) refers to "multiple disabilities arising from damage to the brain acquired after birth" (AIHW, 2015, p. 112). It has many potential causes, including trauma to the head, restriction of oxygen to the brain, stroke, infection or substance abuse (AIHW, 2007). Due to these varied causes, several different terms are often used to describe an ABI. The most common term is "traumatic brain injury" (TBI). However, regardless of the cause, ABI sequelae will depend on factors such as the brain region affected, the brain's plasticity, and the severity of the injury (Williams, 2012). Complicating matters further, acquiring one brain injury increases the risk of further injury (Schneider, 2010). Sequelae of ABI can vary widely, such that no $A B I$ is the same. Symptoms include cognitive disabilities such as memory loss, communication difficulties, lack of insight, difficulty concentrating or problem-solving and understanding social cues, as well as physical disabilities such as slurred speech, chronic pain, sensory impairments, aphasia and impaired balance. In addition, behavioural problems can manifest, including poor judgement, aggressiveness, impulsivity, irritability, self-centredness, problems with regulating emotions and dependence upon others (McMillan \& Wood, 2017; Synapse, 2016; Williams, 2012). While an ABI caused by a noticeable event such as an assault, traffic accident or stroke may be more easily recognised, an $\mathrm{ABI}$ caused by prolonged substance abuse may take years before an accurate diagnosis is obtained (Brighton et al., 2013). Where this occurs, the behaviour of people with an ABI can often be misunderstood as wilful, anti-social behaviour and is therefore more likely to be criminalised (Lansdell et al., 2018a, b; Gould et al., 2017; Brown \& Kelly, 2012). A person with an ABI may not even be aware that they have the condition, or may be unlikely to disclose their diagnosis due to fear of being stigmatised (Lansdell et al., 2018b; Rushworth, 2011). These issues may be further compounded for some groups, such as Aboriginal and Torres Strait Islander peoples in Australia, who are more likely than the broader population to sustain an ABI, and in some communities may also experience additional difficulties in accessing appropriate treatment and support for their condition (Stephens et al., 2014). These many factors have led to ABI being described as a "hidden disability" (Rushworth, 2011, p.4).

A further complicating factor connected to the hidden nature of the disability is the fact that individuals who experience moderate or severe TBIs have prominent adverse outcomes but those with mild TBIs may have symptoms that may not be as obvious and may resolve (Williams, 2012). As noted above, ABI differs widely in terms of cause and pathology although the mild form is more common. For victims of family violence, blows to the head and oxygen deprivation from non-fatal strangulation is common and this oxygen deprivation can lead to anoxic/hypoxic brain injury which may contribute to disability outcomes (Smirl et al., 2019; Zieman et al., 2017).

\section{Review of Studies and Literature}

In recent years, a growing body of evidence has shed light on the association between $\mathrm{ABI}$ and family violence, for both victims (Hunnicutt et al., 2017; Monahan, 2018; Valera, 2018) and perpetrators (Bueso-Izquierdo et al., 2015; Farrer et al., 2012; Pinto et al., 2010). However, as most of this research has originated in the United States, it has invariably relied upon the more narrow definitions of IPV and TBI to investigate the association. As a result, other factors causing an $\mathrm{ABI}$, such as prolonged substance abuse, and family violence occurring outside of intimate partner relationships, are often excluded from analysis. Nevertheless, this important body of literature has identified that ABI may be implicated in both the perpetration, and consequences of, family violence.

\section{$A B I$ and Victims of Family Violence}

As Monahan (2018) notes, exploratory studies have been conducted as early as the mid 1990s into the prevalence of ABI among women in domestic violence shelters and emergency room patients (Monahan \& O'Leary, 1999). A number of similar studies have followed (Kwako et al., 2011; Wong et al., 2014; Zieman et al., 2017). In fact, the rate of $\mathrm{ABI}$ among women who are victims of family violence has recently been described as a "public health epidemic" (Valera, 2018, p. 735). In a 2018 study, 57\% of victims (116 of 203) of family violence attending Victorian hospitals were found with major trauma that involved brain injury, of which 14 of 17 deaths were accounted for because of brain injury (Brain Injury Australia, 2018). Yet, routine assessment for ABI among women accessing domestic violence shelters and emergency room departments rarely occurs (Monahan, 2018). At the same time, Hunnicutt et al. (2017) warn that - while concerning - much of this existing research relies on data collected from only a small subset of people who are victims of IPV, and thus cannot yet be generalized. In addition, Hunnicutt et al. (2017) note that further research into variables including race, education and socio-economic status, as they apply to the experiences of victims of family violence, are crucial. Complicating researchers' abilities to ascertain the extent of this problem is the fact that many cases of family violence, as well as ABI, are likely to go unreported (Monahan, 2018; Murray et al., 2016; Valera, 2018; Zieman et al., 2017). The perpetrator's control over the victim, and the repercussions of the brain injury itself, 
lessen the likelihood that a victim of family violence will seek treatment for their ABI (Hunnicutt et al., 2017; Kwako et al., 2011; Zieman et al., 2017). A mild ABI in particular, is very likely to go undiagnosed (Banks, 2007). Finally, the stigma surrounding family violence is also a potential factor in a victim's decision not to seek treatment and support (Hunnicutt et al., 2017). Ultimately, these many factors compound the invisibility of people with ABI who are victims of family violence; with each risk factor that contributes to the likelihood of obtaining an ABI, simultaneously increasing the risk that the ABI will go undetected.

Victims of family violence are considered particularly vulnerable to sustaining an $\mathrm{ABI}$ because perpetrators will often target the victim's upper body in an attack. For example, assault to the face, head or neck, as well as strangulation, are common forms of violence in this context or causing the victim's head to hit other objects (Kwako et al., 2011; Monahan, 2018; Smirl et al., 2019; Zieman et al., 2017). Abusive incidences result in several short- and long-term consequences that impact both mental and physical health (Cody et al., 2015; Craparo et al., 2014; Iverson et al., 2017). Physical health conditions (e.g. gastrointestinal disorders, chronic pain, headaches), psychiatric symptoms (e.g. affective and mood disorders), and potential alterations to the nervous system (Banks, 2007; Campbell et al., 2018; Iverson et al., 2019; Smirl et al., 2019) are common. Alterations to the nervous system are specific to the prefrontal cortex (involved in cognitive behaviours and decision making processes), hypothalamus (regulation of hormones and autonomic function), amygdala (aid in emotional memory processing, fear responses, behavioural and mood responses to threats in the environment) and hippocampus (interpretation of events and emotional responses) present following injury (St Ivany \& Schminkey, 2016). This is in addition to alterations in arousal and emotional states (such as "Fatigue", "Anxious", "Drowsiness", and "Just Don't Feel Right") or aspects of memory and cognition ("Difficulty Concentrating", and "Difficulty Remembering") (Smirl et al., 2019, p. 1536; see also Baxter \& Hellewell, 2019).

Medical and scientific researchers stress that ongoing and severe abuse can worsen over time with victims being subjected to a higher risk of repeated violence while allowing the ABI to "remain hidden until neurological function degrades into a constellation of cognitive, emotional, and somatic symptoms" (Lifshitz et al., 2019, p. 656; Hunnicutt et al., 2017; Murray et al., 2016; Zieman et al., 2017). Lifshitz et al (2019, p. 656) further stress that "without awareness of the neurological signs and symptoms associated with TBI, individuals with a history of domestic violence and their support network may incompletely comprehend the lasting impact of abuse and trauma" as long-term symptoms have been found to worsen up to 18 months after initial assessment (Iverson et al., 2019), thus derailing support and promotion of overall welfare for victim-survivors. Others have further suggested that "just living in a battering relationship may account for changes in one's cognition and psychological functioning" (Hunnicutt, 2017, p. 475). For these reasons, there are significant long-term consequences arising from family violencerelated ABI, even after a victim may have left their abusive partner (Monahan, 2018). For example, as a victim may lose their ability to function independently, they may become more dependent on the perpetrator, making it more difficult for them to leave. They may also lose the ability to keep their employment, or effectively care for children (Hunnicutt, 2017; St Ivany \& Schminkey, 2016; Jackson et al., 2002). Adding to these complexities, co-morbid mental health issues may both precede or follow the ABI and the family violence (Hunnicutt et al., 2017). Furthermore, victims of family violence may likely experience other compounding health issues including substance abuse (Hunnicutt et al., 2017; St Ivany \& Schminkey, 2016) - which may, in turn, make diagnosis of their acquired brain injury more difficult (Banks, 2007).

Child abuse in all its forms is recognised as an adverse childhood experience (ACE)(Kalmakis \& Chandler, 2014) and is linked to $\mathrm{ABI}$ exposure and family violence having longstanding ramifications extending into adulthood (Felitti et al., 1998). Recent research by Baidawi and Piquero (2020) has confirmed prior research that over-representation and systematic entrenchment of young persons with ACEs in criminal justice systems include a significant number of young people with neurodisabilities (including ABI). A range of factors and incidences including family violence, neglect, substance misuse are indicators of ACEs but also contribute to the acquisition of ABIs (Baidawi \& Piquero, 2020). This position is supported by a 2018 US study that found "Sexual abuse, emotional abuse, physical abuse, household mental illness and household substance abuse were significantly associated with ABI ..." (Guinn et al., 2019, 514).

\section{$A B I$ and Family Violence Perpetrators}

The first association between brain injury and the perpetration of family violence was made almost thirty years ago (Rosenbaum \& Hoge, 1989), and studies have repeatedly found a correlation since (Bannon et al., 2015; Farrer et al., 2012). These studies commonly find heightened prevalence of brain injury, or evidence of reduced executive functioning, among family violence perpetrators (Farrer et al., 2012; Pinto et al., 2010). According to Farrer et al., "the biological factors associated with IPV are in concordance with findings demonstrating an association between traumatic brain injury (TBI) and aggression and violence, behaviors known to be present in perpetuators of interpersonal violence" $(2012$, p. 2). 
Most perpetrators have been found with histories of brain injury and trauma that has diverted typical cognitive, emotional, and somatic development (Brain Injury Australia, 2018; Lifshitz et al., 2019; St. Ivany \& Schminkey, 2019). Brain injury has also been linked to aggression (Buckley et al., 2017). Family members, for example, have reported noticeable differences in the levels of aggression of loved ones who have sustained an ABI through head trauma (Ali \& Naylor, 2013b; Bannon et al., 2015). Furthermore, ABI is over-represented in prison populations around the world (Durand, 2017; O'Rourke et al., 2017; Shiroma et al., 2010). A strong causal link between ABI and criminal offending is not, however, supported in the literature. As Colantonio et al. (2014) have noted, only a few studies have found "a strong correlation between TBI and crime but made no conclusive causal association" (p. 6).

Despite repeated associations between ABI and family violence found in the existing literature, causation has not been proven, and many studies suffer from methodological problems (Buckley et al., 2017; Bueso-Izquierdo et al., 2015). In particular, Buckley et al. (2017) note significant variation in definitions of TBI and aggression used amongst the studies they reviewed. Other studies have been found to lack diversity among sample participants (Bueso-Izquierdo et al., 2015). Researchers therefore stress that, while ABI or reduced executive functioning is common among family violence perpetrators, "head injury alone cannot fully explain the occurrence of violence" (Bannon et al., 2015, p. 325).

There are also a host of other co-occurring factors which are likely to contribute to and exacerbate the occurrence of both family violence and ABI. These include alcohol and other drug use (Easton et al., 2008; Fernandez-Serrano et al., 2011), "an attitude condoning violence" (Hunnicutt, 2017, p. 478), "gender power disparity" (Ali \& Naylor, 2013a, p. 612), chronic life stress (Sprague et al., 2011), chronic pain associated with physical health conditions (Crane \& Easton, 2017), and child abuse earlier in life (Stern, 2004). According to Ali and Naylor, the association between alcohol abuse and family violence "remains controversial and debatable" and they conclude that it is "difficult to establish a causal link" between the two (2013b, p. 379). Nonetheless, they agree that alcohol abuse is likely to be an "important contributing or facilitating factor" in many cases of family violence (Ali \& Naylor, 2013b, p. 379). Farrer et al. (2012) also note the likelihood of a complex relationship between the two issues.

In Victoria, Australia, where our research was conducted, a recent Royal Commission into Family Violence recommended that " $[t]$ he Victorian Government fund research into the prevalence of $[\mathrm{ABI}]$ among family violence victims and perpetrators" with perpetrators with a TBI having a higher offending rate than the general population (State of Victoria, 2016, p. 193). In response, the Victorian Department of Health and Human Services commissioned a study into the association between brain injury and family violence (Brain Injury Australia, 2018). That study conducted a systematic literature review and analysed hospital data which uncovered "a strong association between brain injury and family violence" for victims of family violence (Brain Injury Australia, 2018, p. v). This study also found that the rate of brain injury among male perpetrators was approximately $60 \%$, which is double the rate found in matched community samples (Brain Injury Australia, 2018, p. vii). However, beyond summarising the existing literature, the study did not collect any data or report new findings on the prevalence of ABI amongst perpetrators of family violence. As such, the prevalence and nature of the association between $\mathrm{ABI}$ and family violence perpetration in Australia remains under-researched.

\section{Prior Qualitative Studies - Links Between Family Violence and $A B I$}

Studies continue to report strong relation between brain injury and family violence (also commonly referred to as domestic violence DV, intimate partner violence IPV), as well as persistent and significant gaps, miss-recognition, and under-recognised forms of violence-related brain injury in service responses (Brain Injury Australia, 2018; Lifshitz et al., 2019; Nemeth et al., 2019). These "unseen" and "invisible" impacts on victim-survivors" neurological and cognitive systems not only make women more likely to experience greater rates and additional forms of genderbased violence (Maher et al., 2018; see Nemeth et al., 2019 for long-lasting unrecognised impacts, Iverson et al., 2019, p. 19 for "silent injury"; see also Lifshitz et al., 2019 for under-recognition and under-representation of TBI for IPV and DV victims compared to brain injury and concussions on athletes and military servicemen), but also harder to successfully escape long-term abusive relationships due to the impact of traumatic brain injury (Donkelaar, 2018).

Family violence, especially physical abuse, often results in a myriad of negative physical health issues, including those that affect brain function (Nemeth et al., 2019, p. 745). Although there is little direct evidence for the potential link between IPV and TBI-induced brain dysfunction (Smirl et al., 2019), an increasing amount of research identifies association between family violence victimisation and brain injury, thus supporting long-standing knowledge within advocacy community that bruising to the face and neck, along with suffocation (Monaghan, 2018; Taliaferro et al., 2001) are all common occurrences for DV survivors (Nemeth et al., 2019).

Intersectionality and compounding impacts of family violence and IPV incidences interact and produce health inequalities (Bowleg, 2012; St Ivany et al., 2018), with repeated cycles of abuse as a significant qualitative finding 
when instability and structural violence is taken into account as a result of childhood trauma and historical state intervention/control (St. Ivany \& Schminkey, 2019). However, research does not include the study of survivors who have not accessed services but are living with mild but recurrent brain injury with a frequency and intensity that may never be captured, and likely exceed reports for soldiers and athletes (Lifshitz et al., 2019; Nemeth et al., 2019; Prince \& Bruhns, 2017). Further studies also stress that limitation in adult studies on lifetime trauma neglect assessment and consideration of impacts from childhood trauma (Smirl et al., 2019).

\section{Methodology}

Our conclusions about the links between family violence and $\mathrm{ABI}$ are drawn from research that explored the experiences of people with $A B I$ in the criminal justice system in the state of Victoria, Australia. A better understanding of why people with $A B I$ were over-represented in that system was sought. A private philanthropic grant administered by the Office of the Public Advocate (OPA) in Victoria, Australia, funded our research. Data was gathered from over 100 interviews with stakeholders and people with lived experience of ABI. Qualitative content analysis (Braun \& Clark, 2006) determined the dominant themes and sub-themes, as well as the less common themes, and inductive interpretive content analysis identified themes commonly found in previous published research and themes that appeared unique to, or unanticipated in, our data, such as the FV theme upon which this article focuses. While FV was not anticipated to be a strong, emerging theme, our qualitative data analysis nevertheless uncovered a concerning relationship between ABI and family violence, as participants' too often described associations between experiencing $\mathrm{FV}$ and acquiring an $\mathrm{ABI}$ or acquiring an $\mathrm{ABI}$ and subsequently perpetrating FV. Both the former and the latter associations led to people with an $\mathrm{ABI}$ encountering the criminal justice system either as a victim or offender and, too often, both.

\section{Participants}

We recruited participants from justice agencies in Victoria, Australia, as well as a number of community service organisations and community legal centres that worked alongside the justice system. Participants (see Table 1) held various professional roles, including judicial officers from a range of court tiers, lawyers, police prosecutors and social service providers; while others included people with $A B I$, their families and carers. Forty-five participants were men, and 56 were women. Consequently, the research design used a combination of non-probability sampling techniques, including purposive sampling, and snowballing methods (Berg (2006) for chain referral sampling), to recruit participants who worked in key stakeholder organisations. This involved approaching a range of organisations to disseminate invitations to staff to be interviewed for the study, and placing

Table 1 Participant Details

\begin{tabular}{|c|c|c|c|}
\hline Participant group & Participant Code & Organisation & $\begin{array}{l}\text { Number of } \\
\text { interviews } \\
\text { conducted }\end{array}$ \\
\hline County Court Judges & $\mathrm{J}$ & County Court of Victoria & 8 \\
\hline Magistrates & M & Magistrates' Court of Victoria & 7 \\
\hline Court Staff & $\mathrm{CS}$ & Magistrates' Court of Victoria & 5 \\
\hline Tribunal Members & TM & Victorian Civil and Administrative Tribunal (VCAT) & 3 \\
\hline Police Prosecutors & PP & Victoria Police & 6 \\
\hline OPP Staff & OPP & The Office of Public Prosecutions & 2 \\
\hline VLA Lawyers & LA & Victoria Legal Aid (VLA) & 10 \\
\hline CLC Lawyers & CL & Community Legal Centres & 8 \\
\hline Financial Counsellors & $\mathrm{FC}$ & Community Legal Centres & 2 \\
\hline Service Providers & SP & A range of community, support and health organisations & 25 \\
\hline People living with ABI & P.ABI & $\begin{array}{l}\text { Included ex-prisoners and people currently or formerly experiencing addiction, } \\
\text { who accessed the support of community service organisations participating in this } \\
\text { research project }\end{array}$ & 22 \\
\hline $\begin{array}{l}\text { Family members of peo- } \\
\text { ple living with ABI }\end{array}$ & FM.ABI & Accompanied people living with ABI who participated in this research project & 3 \\
\hline Focus Group & FG & $\begin{array}{l}\text { Selected social workers and psychologists from a speciality acquired brain injury } \\
\text { service }\end{array}$ & 1 \\
\hline Total & - & - & 102 \\
\hline
\end{tabular}


posters in community service organisations and legal centres. Support letters and endorsement was also included to aid in recruitment and snowballing of interviewees living with an ABI and other personnel in community legal and health service centres. Representation was achieved by the participants being drawn from different areas of the criminal justice system. We had 11 sub-sets of participants as per Table 1 and, in order to obtain a qualitative research sample of each cluster, the size of the total sample grew to 101 . We interviewed participants until we reached saturation point - where no new insights or perspectives were emerging. As this was a qualitative research project we did not seek representative/generalisable findings (as expected in quantitative research) rather we sought to explore the diverse insights of participants with life and professional experiences that would contribute to knowledge about this vulnerable group.

\section{Procedure}

Ethics approval was sought from the Monash University Human Research Ethics Committee, as well as from a number of other ethics committees of the organisations from which our study participants were sourced. This included the Department of Justice Human Research Ethics Committee in Victoria. All participants were provided with a Plain Information and Explanatory Statement and Consent Form. During this time, they were also informed about the aim of the research, the use of the results and the nature of their involvement. Prior to the interviews being conducted we obtained written informed consent from all participants. We also worked in collaboration with an ABI specialist support worker to develop user-friendly project explanation and consent forms for participants with an ABI. These forms explained information about the study and the participants' rights in a plain and uncomplicated manner. For the majority of interviews with participants with $\mathrm{ABI}$, verbal consent was also sought on three occasions before the interviews took place; and these participants were able to have a support person (either a family member or carer) accompany them in the interview. Six of the interviews conducted with people with ABI were 'walk-ins', where they were recruited for the study at the time of attending a community service organisation in person. Participants with an ABI also received a $\$ 50$ retail gift voucher for participating. The 22 people living with ABI who participated in the project had been clinically assessed and diagnosed previously by medical specialists as having an $\mathrm{ABI}$ and although there were degrees of severity of the illness, approximately $90 \%$ were in the mild-moderate range but in all cases, the injury was categorised as permanent.

\section{Data Collection and Analysis}

Interview data were collected over the course of one year, with 101 interviews and one focus group taking place between February 2015 and March 2016. Most were conducted individually face to face, except for four interviews which were conducted via telephone. Visits to respective justice institutions typically took half a day, with interviews spanning from 45-60 min long depending on participants' availability. The focus group ran for over 2 hours and involved a number of clinicians from one organisation who is a recognised service provider in the State. The focus group, requested by the organisation itself, was beneficial as it allowed for interviewees to have an open dialogue where inconsistencies and gaps were raised during the collegial "back-and-forth" (Goss \& Leinbach, 1996 for groups up to fifteen; and Kitzinger, 1995 for benefits of discussion and interaction). Interviews were conducted by principal researchers with backgrounds in either law, social work or criminology, all of whom have extensive experience in conducting both qualitative research and interviews. The social work specialist researcher sat on all interviews involving persons with an $\mathrm{ABI}$ as part of an ethics approval requirement. All persons living with an $\mathrm{ABI}$ had the opportunity to have a care person with them during the interview if they so required. The Plain Information Statements made it clear that they could terminate the interview at any time and who they could contact if they felt distressed pre- and post-interview. In order to preserve confidentiality the data from the focus group was not separated out but was absorbed into the general findings where they were denoted collectively as a Service Provider.

Interviews were semi-structured, and the questions were pre-determined and shared with particular participants (specifically Judge and Magistrates) in advance (again as part of a requirement of the ethics approval). Persons living with an ABI had a different list of questions from, for example, justice system staff and these questions were worded using appropriate terminology following advice from service providers who work with persons with an ABI. The content areas related to persons living with an $\mathrm{ABI}$ focused on their experiences of contact with the criminal justice system including processes related to the police, courts, judges, legal practitioners, prison services (if appropriate) and disability support services. Interview questions for the other named participants were similarly focused. None of the pre-determined questions specifically asked participants about matters related to family violence or were designed to elicit such responses given that this was not the prime focus of the project. However, the semi-structured nature of interviews also allowed dialogues to be tailored to each participant group and for themes to be raised by participants in a spontaneous manner and expanded upon. 
The questions that we believe drew out the link between ABI and family violence included: "Where do you live and with whom?"; "Can you tell us more about your ABI and how it has changed your life?"; "How did you come into contact with police or the courts?"; "What would you like police, lawyers and the courts to know about you?". Similarly worded questions of service providers, lawyers, judicial officers and Court Staff, included: "How is it identified that a person has an ABI?"; "What is your experience of people with an ABI charged with offences in your court [or practice]?"; "Does this group present with 'special circumstances' such as, for example, homelessness, drug use, family breakdown?". It was this spontaneous aspect of the semistructured interviews that gave rise to the emerging dialogue as to family violence raised by a variety of stakeholders and persons living with an ABI themselves.

A research assistant transcribed the recorded interviews, and participants were permitted to review and amend their transcripts, if they desired. Only two participants (after receiving a copy of their respective transcript) requested a change to be made (related to grammatical concerns) which, in both instances, was not acted upon.

The NVivo (11.0) qualitative data analysis software aided both the inductive and deductive content analysis methods. The thematic analysis and coding were utilised during the two main states of analysis and developed with close correspondence with the three principal researchers and the research assistants regularly discussed the progress and outcomes of the thematic analysis and coding of the research data, which involved three key phases (Braun \& Clarke, 2006). The first phase consisted of open coding, treating each theme and case study as a unit of analysis to be understood as an independent set of elements. Two subsequent iterative coding processes also established relationships between the elements. Following the first stage of analysis, a second research assistant developed a coding scheme to cross-analyse and compare the data set between interviews, reports, academic studies and grey literature and produced a table of codes. The data was then double-coded against all the themes identified in the research interviews, previous findings and the literature review. All research assistants had training in, and experience of, qualitative coding prior to joining the research team. The themes that emerged from the participant interviews were mapped against and compared to themes which had been identified in the existing literature on disability, $\mathrm{ABI}$ and the criminal justice system (reviewed in Lansdell et al., 2018a, b; Eriksson et al., 2019). The research assistants met regularly and reviewed and compared the data to strengthen validity and inter-rater reliability. We did not seek a Kappa score. Instead we checked inter-rater agreement through dual coding of the same data and checking for coding consistency identifying relationships between the data set, previous research on adults with $\mathrm{ABI}$ and existing literature. Braun and Clark (2006) espouse this method of double coding. Coding consensus meetings were held to review transcripts with qualitative content analysis chosen to analyse the transcripts as it allows for a "systematic but not rigid" approach (Altheide \& Schneider, 2013, 26). Some codes (like family violence) emerged unexpectedly as transcripts were coded and were subsequently further explored in current literature to determine their uniqueness to our study. The constant comparison within data sets and documents further allowed themes to be drawn out and ranked in terms of significance (Charmaz, 2014).

\section{Results}

Three key themes, related to this association between ABI and family violence, arose in our research. First, our results suggest that $\mathrm{ABI}$ can be a factor for both victims and perpetrators of family violence, who come into contact with the justice system. Second, for some perpetrators of family violence who have an $\mathrm{ABI}$, the sequelae of their ABI may at least partially account for the nature of their offending and, finally, where ABI and family violence co-occur, they often do so in combination with other issues such as substance abuse and mental health.

\section{Theme 1: Acquired Brain Injury and Criminal Offending}

We do not contend that our findings suggest a causal relationship between ABI and family violence. However, our findings suggest a concerning association, both for family violence victims and perpetrators.

\section{Sub-theme: Family Violence Leading to an ABI}

In our study, women with an ABI who encountered the criminal justice system, had too often experienced intimate partner violence, and too many participants also reported a direct link between such violence and acquiring an ABI. While our study cannot confirm a causal link, it nonetheless highlights participants' perceptions that the relationship between these two factors is strong. Various participant groups in our study reported this association, including service providers, police prosecutors and court staff:

We know that most of the women that we see as offenders have been victims of family violence or childhood abuse - Court Staff 5 
Mainly strokes, domestic violence, car accidents - they are our main [common causes of ABI]. - Service Provider 12

Two participants described how their former partners' violence had directly contributed to their ABI:

I actually had my head stomped on by an ex-partner three times... I feel stupid, I get really depressed from it...-Person with ABI 21

I've had so much violence done to my brain [by my partners] that I actually couldn't communicate with others.... I couldn't put a sentence together. - Person with ABI 22

Unfortunately, however, an offender who has an ABI emanating from family violence may experience difficulties obtaining a clear and accurate diagnosis of the condition. This is because the nature of family violence (often occurring over a prolonged period of time) means a single, discernible traumatic event is not always apparent to explain the $\mathrm{ABI}$ :

Someone with a stroke knows that the stroke caused the ABI, but someone with domestic violence doesn't know what incident it was or what it was. Service Provider 12

Participants in our study also routinely attributed an offender's ABI to earlier childhood abuse (ACEs). This was seen to be the case for both male and female offenders. Participants described their clients' histories of significant violent victimisation, which often led to developmental delays, alcohol and other drug abuse, and co-morbid mental health challenges:

Child abuse. I'm confident that the majority of people that have substance abuse [related] acquired brain injury, alcohol-abuse [related] acquired brain injury or assault [related] acquired brain injury, when you go back into the story there is a lot of abuse whether it is verbal, physical, emotional, financial - that is highly common. - Service Provider 13

After what my dad did to me when I was younger, I went downhill. My dad sexually assaulted me, bashed me every night, that's where I got my scars on my head from - my dad. - Person with ABI 17. I came home, had a few drinks whatever but I was fine and I came out to the kitchen and my mum and dad were having a fight for some reason. Everything was okay and I went outside to the backyard and my dad said [he] would make me a cup of tea and I just mentioned to him... my mum said he was not happy with the Christmas present that I gave him.... That was it, I walked back inside and he king hit me in the back of the head and I fell directly, my whole body directly on to my head. - Person with ABI 11

\section{Sub-theme: Family Violence, $\mathrm{ABI}$ and Subsequent Offending}

Child abuse, maltreatment and neglect - in particular, sexual abuse - have been found to be associated with an enhanced risk of offending later in life (Cutajar, 2011; Currie \& Tekin, 2006). Furthermore, Colantonio et al. (2014) found a concerning connection between early childhood abuse and the prevalence of TBI among a sample of offenders, which was particularly pronounced for the women in their study. Many participants in our study drew links between the abuse that offenders suffered in childhood, and their subsequent offending and proclivity for violence, later in life:

...we get a lot of persons who say, "I've had a bottle hit over the head", "my father kicked me". I don't like to sound light over this but that is the sort of thing that we hear. This is life... "My father belted me up as a child", or any number of things. And then suddenly 30 years later they say, "Why has this person assaulted someone so badly". They try to trace back. - Judge 3

While not all offenders with an ABI commit family violence, a number of lawyers, police prosecutors and court staff interviewed in our study noted that family violence offences were common among the offenders with $\mathrm{ABI}$ with whom they came into contact:

Family violence is a big one... actually I would say family violence and assault-related offences is [sic] probably the more prevalent that I have found. - Police Prosecutor 6

...domestic violence, assault type matters - a lack of ability to control his emotions and anger. There are those types of things. - Community Lawyer 3.

\section{Theme 2: Perpetrators with ABI and Family Violence Offending}

As discussed earlier, common sequelae of an ABI may include difficulty in regulating emotions and problemsolving, not understanding social cues, lacking insight into behaviour, and being self-centred, aggressive, impulsive, and easily irritated (Synapse, 2016; Williams, 2012). Some studies in the United States have found evidence of ABI, or levels of functioning which suggest the possibility of ABI, amongst perpetrators of family violence (Buckley et al., 2017; Farrer et al., 2012; Pinto et al., 2010). 


\section{Sub-theme: $A B I$ and Repetitive, Impulsive and Violent Family Violence and Other Offending is Common and Serious}

Many participants in our study - especially those working within justice system agencies - described how offenders with $\mathrm{ABI}$ often committed family violence offences as well as other repetitive, impulsive or violent offences:

...often they are quite serious. If you think about the impulsivity... if you think about the lack of executive function or diminished executive function, those kinds of offences where they can't organise themselves. You have those sorts of offences, which might be driving or driving unregistered or all those sorts of things. Then you get into quite violent offending, family violence. - Magistrate 1

\section{Sub-theme: ABI Family Violence Offending, Limited Understanding, and Resultant Isolation From Family and Friends}

A number of participants described how many of the offenders with an ABI with whom they came into contact, would often commit family violence offences without necessarily understanding the meaning or consequences of their actions:

The person's offending was family violence... he continued to breach intervention orders, he couldn't understand why his former partner wanted no contact with him... there was a repetitiveness; we're talking 20 or 30 breaches a day knocking on the front door, racking up the breaches to the point where it is now an indictable offence to breach that often. - Court Staff 5

The pressure on, or breakdown of, family and social networks has been recognised as a significant issue in the lives of people with ABI (Brown \& Kelly, 2012; Holloway, 2014). Often this breakdown can lead to social isolation, in turn contributing to mental illness and other difficulties, and aggravating the experience of their ABI (Holloway, 2014):

I eventually...lost most of my friends, probably $95 \%$ of the people I knew and within a year I had not seen them. I lost my relationship after two years - Person with $\mathrm{ABI} 3$

Our participants described how the nature of offending among many offenders with ABI frequently included impulsive, aggressive, incessant behaviour sustained over a prolonged period, usually until the person had driven away most of their personal support networks:

For one guy that I had, his children and his grandchildren don't want anything to do with him and he was always just distraught about that; "I never did anything to deserve this" even though there were multiple breaches of intervention orders. A lot of the time it has just gone on for so many years, their substance abuse or they have stolen from their family or they have damaged property or they have hurt family members, they have been violent in the house, they have scared the kids, they have been aggressive and it is all over - [the family] don't want anything to do with them anymore. - Court Staff 2

One participant with an $\mathrm{ABI}$ reflected on the impact that his disability had on his behaviour towards his family:

I think the saddest thing with my $\mathrm{ABI}$ in the early days was the professionals didn't tell my family - the ones that I loved the most are the ones that I was going to tear to pieces. - Person with ABI 1

\section{Theme 3: Family Violence and Acquired Brain Injury with Its Multiple Co-morbidities and Accompanying Life Challenges}

Despite the fact that many of our participants drew connections between offenders' ABIs and their perpetration of family violence, it was clear that neither the presence of an ABI, nor family violence, occurred in a vacuum. As the following staff member of the Magistrates Court of Victoria notes, factors which can impact on the lives of people with $\mathrm{ABI}$ appearing in the justice system can include:

Drugs and alcohol, mental health, family violence or anger management, child protection, Centrelink, vocational, housing, it can sometimes be just isolation, suicidal intentions or risk. - Court Staff 3

Previous studies have found that a range of co-morbid conditions such as substance abuse, mental illness or other disability accompany an $\mathrm{ABI}$, and in the absence of adequate support, can further exacerbate the effects of the condition (Corrigan \& Deutschle, 2008; Gould et al., 2011; McHugo et al., 2017; Moore \& Haysom, 2014). Participants in our study consistently described the 'milieu' of disadvantage, trauma and violence, which they perceived to be common within the lives of offenders with ABI (regardless of whether those offenders were victims and/or perpetrators of family violence). Judicial officers were particularly aware of the complex life histories of those who appear before them:

...often you are dealing with people who live very chaotic lives and there is a multitude of problems. There is socio-economic discrimination - they're at the bottom of the heap - there is associated drug use, there is domestic abuse, there is a huge amount of trauma and 
physical violence in their lives probably because of the milieu. People in that situation often acquire a brain injury, seems to be fairly common. - Judge 1

In particular, members of the judiciary perceived alcohol and other drug misuse as one of the most frequent cooccurring issues that offenders with an ABI experienced:

We very rarely get someone with just an ABI. It is usually what is coming before us is the ABI and alcohol or the ABI and Ice [methamphetamine]. That sort of thing. Then there is the family breakdown, they can't live at home anymore with mum - she has had enough. Then there is the intervention order granted, protecting the family. - Magistrate 1

These observations add weight to the existing literature, which finds that people with ABI frequently have co-morbid substance abuse and mental illness diagnoses (Corrigan \& Deutschle, 2008; McHugo et al., 2017). It can often be unclear, however, whether factors associated with ABI, such as substance abuse, preceded or followed the person's ABI. Indeed, many of our participants described how people with prolonged substance use induced ABI, rather than a discernible traumatic event, often suffered for years without a diagnosis:

I think it is difficult with an ABI because it is so difficult to diagnose ... I mean some people wouldn't even know that they had an ABI. Sometimes there is also the overlay of all the drug and alcohol and/or mental health issues that can cover up a lot of things and until you start dealing with that you don't realise that you have the underlying issue. - Magistrate 2

\section{Discussion}

People with ABI can encounter a range of barriers and difficulties within the community, which may increase their likelihood of both committing criminal offences, including family violence, and/or becoming a victim of a criminal offence, such as family violence, and consequently encountering the criminal justice system (Lansdell et al., 2018b; Hughes et al., 2012; McKinlay et al., 2014). Furthermore, the varied factors which may contribute to the risk of acquiring an ABI may mirror those factors which make contact with the justice system more likely (Rushworth, 2011). For example, McKinlay et al. (2014, p. 499) have described ABI and offending as having a "shared etiology" [sic]. While this article does not contend that ABI is a single cause of family violence perpetration, or a cause of offending more generally, our preliminary findings suggest that ABI should be considered one potential contributing factor in both the victimisation and perpetration of family violence, among people who come into contact with the criminal justice system as offenders. Participants in our study described a complex interplay of factors, which, in their view, contributed both to the presence of ABI in offenders' lives and the nature of their offending. The fact that first responders can mistake the identifying features of ABI behaviour for substance abuse is an issue.

In Victoria, Australia, where our study was conducted, we purport that for offenders with an ABI who perpetrate family violence, consideration of the above factors is particularly important. A recent Royal Commission into Family Violence held in Victoria heard that:

...there are no behaviour change programs for perpetrators with learning or mental health disabilities, that restrict their capacity to learn in a group setting. The evidence before the Commission was that they are currently screened out of mainstream men's behaviour change programs. (State of Victoria, 2016, p. 191)

This suggests that perpetrators of family violence, with neurodisabilities such as ABI, may have been systematically excluded from the most common intervention designed to curb family violence in Victoria. The additional factors of disadvantage and co-morbidities that offenders with ABI who come into contact with the justice system often experience, are likely to create even further barriers to their accessing appropriate behaviour change programs, even where their $\mathrm{ABI}$ is not formally diagnosed. The consequences of this exclusion are ultimately likely to impact on both victims and perpetrators of family violence alike. It is relevant for law makers in other jurisdictions to also consider if these same disadvantages exist.

To assist with identification of at-risk ABI individuals, refinement and development of screening tools should be considered such as the Classification of Violence Risk (COVR) assessment tool which was developed for clinicians to assist in their estimation of the risk of violence that an individual with a mental disorder pose (Monahan, 2010). COVR was developed on the basis of the MacArthur Violence Risk Assessment Study (MacVRAS, see Monahan et al., 2010), one of the largest, most robust and renowned studies investigating factors that influence whether a person discharged from a psychiatric facility will be violent following discharge. This tool appears to be largely adopted across the United States, although it was recently independently tested in North-West England on 124 participants where COVR was reported to lack in demonstration of significant validity in predicting future violence (Doyle et al., 2010). Lifshitz and et al. (2019) also recommended post traumatic stress disorder (PTSD) assessment and associated affective symptoms as another component when considering male perpetrators and attempting to identify their risks for violence. Smirl et al. (2019), conducted their research 
using Valera and Berenbaum's (2003) Brain Injury Severity Assessment (BISA) tool designed to elicit the number, severity and time-course of potential TBI incidences which resulted in alterations to consciousness (e.g. seeing stars or spots, blacked out, felt dizzy or stunned, felt disoriented, events of memory loss) experienced by IPV survivors. This tool has yet to be formally tested for reliability and validity although it has been previously shown to be sensitive to reductions in functional connectivity (Valera \& Kucyi, 2017).

Finally, we wish to raise an important recommendation for studies measuring the prevalence of brain injury among family violence victims and perpetrators. The existing literature, predominantly conducted in the United States, almost exclusively relies on the more narrow term of TBI rather than the umbrella term of ABI when considering its association with family violence perpetration (see for example Bannon et al., 2015; Buckley et al., 2017; Crane \& Easton, 2017; Farrer et al., 2012; Pinto et al., 2010). In practical terms, however, the sequelae of both ABI and TBI are likely to be the same; a TBI is simply an ABI caused by a traumatic injury to the head. In the Australian context, an ABI is recognised as a brain injury incurred after birth "regardless of cause" (AIHW, 2007, p. 2). As explained earlier, other causes can include stroke, infection, loss of oxygen to the brain, and prolonged substance abuse (AIHW, 2007). Given our research participants' important insights, we recommend the necessary consideration of substance abuse-related ABI and its potential association (along with other factors) with the perpetration of family violence. Many current studies grapple with the family violence perpetrator with an ABI experiencing co-occurring substance abuse, without considering that the perpetrator's ABI may have stemmed from excessive drug use. For similar reasons, it is important that studies measuring the prevalence of $\mathrm{ABI}$ among victims of family violence include not only ABI emanating from a head trauma but ABI resulting from asphyxiation. As Monahan (2018) notes, asphyxiation (following strangulation) is a common form of family violence.

Narrow nomenclature may result in both limited research results and inadequate interventions and supports. A broadened definition allows for an examination of individuals with hypoxic/anoxic injuries (for example, loss of oxygen due to substance abuse and non-fatal strangulation) in addition to various forms of TBI (for example, violence-related, car accidents). If the $\mathrm{ABI}$ remains undiagnosed for reasons advanced above, there will be a lack of opportunity to engage with community activities and organisations that may be able to provide positive support, monitoring and potentially reduce disintegration of family relationships through family violence. Police and health professionals, as the main and first responders to family violence incidents, are in the best position to facilitate the diagnosis of ABI. Educating them as to their responsibilities in this respect and learning $\mathrm{ABI}$ awareness strategies, should be a future direction for both research and training in this sphere.

\section{Conclusion}

Our study concerned the experiences of persons with ABI who came into contact with the justice system in Victoria, Australia. Our findings strengthen the first and only study into ABI and family violence in Australia, which reported an association between these two factors for both victims and perpetrators (Brain Injury Australia, 2018), as well as providing further important insights from participants' lived and professional experiences. Importantly, our findings suggest that further research into the relationship between ABI, family violence and other factors, such as substance abuse, mental illness and socio-economic disadvantage - for both victims and offenders - is warranted. We also recommend that any future research should adopt a broader ABI definition rather than TBI, to ensure that ABI caused by, for example, substance abuse and asphyxiation is included. We believe an intersectional understanding of family violence and TBI/ $\mathrm{ABI}$ in social ecological contexts, aiming to understand brain injury at both individual and population levels, is necessary. We also urge the need to both work with individuals and foster collaboration between services to improve treatment, approaches, and services for persons living with an ABI. This could include safe houses, counselling, advocacy and medical facilities that focus primarily on identification and treatment of brain injury. Increased awareness of an ABI by police and other intervention agencies including corrections officers and service providers will enable medical assistance to be administered earlier and other services to be offered. Assessment tools and interventionist programs which are largely absent for this group need to be either further refined or developed if we are to reduce the scale of future harm generated by family violence, $\mathrm{ABI}$ related incidents.

Acknowledgements The authors wish to acknowledge the research assistance of Dr Michelle Sibenik and Ariel Yap.

Funding The authors wish to acknowledge the Office of Public Advocate, Victoria through whom funding was obtained for this research in relation to the broader project title An Examination of the interaction of people with an Acquired Brain Injury and the Criminal Justice System.

\section{References}

Altheide, D. L., \& Schneider, C. J. (2013). Qualitative Media Analysis. Sage.

Australian Institute of Health and Welfare. (AIHW). (2007). Disability in Australia: acquired brain injury (Bulletin. 55). Canberra: Australian Government. 
Australian Institute of Health and Welfare. (AIHW). (2015) The health of Australia"s prisoners (Cat. No. PHE 207). Canberra: Australian Government.

Australian Institute of Health and Welfare. (AIHW). (2018). Family, domestic and sexual violence in Australia 2018 (Cat. No. FDV 2). Canberra: Australian Government.

Ali, P., \& Naylor, P. (2013a). Intimate partner violence: a narrative review of the feminist, social and ecological explanations for its causation. Aggression and Violent Behavior, 18, 611-619. https:// doi.org/10.1016/j.avb.2013.07.009

Ali, P., \& Naylor, P. (2013b). Intimate partner violence: a narrative review of the biological and psychological explanations for its causation. Aggression and Violent Behavior, 18, 373-382. https:// doi.org/10.1016/j.avb.2013.01.003

Baidawi, S., \& Piquero, A. R. (2020). Neurodisability among children at the nexus of the child welfare and youth justice system. Journal of Youth and Adolescence. https://doi.org/10.1007/ s10964-020-01234-w

Banks, M. (2007). Overlooked but critical: traumatic brain injury as a consequence of interpersonal violence. Trauma, Violence \& Abuse, 8, 290-298. https://doi.org/10.1177/1524838007303503

Bannon, S., Salis, K. \& O'Leary, D. (2015). Structural brain abnormalities in aggression and violent behavior. Aggression and Violent Behavior, 25(Part B), 323-331. https://psycnet.apa.org/doi/ 10.1016/j.avb.2015.09.016

Baxter, K., \& Hellewell, S. C. (2019). Traumatic brain injury within domestic relationships: Complications, consequences and contributing factors. Journal of Aggression, Maltreatment and Trauma, 28(6), 660-676. https://doi.org/10.1080/10926771.2019.1602089

Berg, S. (2006) "Snowball sampling - I." in: Kotz, S., Read, C., Balakrishnan, N., Vidakovic, B. (Eds.), Encyclopedia of Statistical Science. Hoboken, N.J: Wiley.

Bowleg, L. (2012). The Problem with the Phrase Women and Minorities: Intersectionality - an Important Theoretical Framework for Public Health. American Journal of Public Health, 102(7), 12671273. https://doi.org/10.2105/AJPH.2012.300750

Brain Injury Australia. (2018). The Prevalence of Acquired Brain Injury Among Victims and Perpetrators of Family Violence. Brain Injury Australia.

Braun, V., \& Clark, V. (2006). Using Thematic Analysis in psychology. Qualitative Research in Psychology, 3(2), 77-101. https:// doi.org/10.1191/1478088706qp063oa

Brighton, R., Traynor, V., Moxham, L., \& Curtis, J. (2013). The needs of people with alcohol-related brain injury (ARBI): a review of the international literature. Drugs and Alcohol Today, 13(3), 205-214. https://doi.org/10.1108/DAT-12-2012-0011

Brown, S., \& Kelly, G. (2012). Issues and inequities facing people with acquired brain injury in the criminal criminal justice system. Melbourne: Victorian Coalition of ABI Service Providers Inc. http://diverge.org.au/pdf/brown_kelly_2012.pdf.

Buckley, L., Kaye, S., Stork, R., Heinze, J., \& Eckner, J. (2017). Traumatic brain injury and aggression: a systematic review and future directions using community samples. Aggression and Violent Behaviour, 37, 26-34. https://doi.org/10.1016/j.avb.2017.08.004

Bueso-Izquierdo, N., Hart, S., Hidalgo-Ruzzante, N., Kropp, P., \& Pérez-García, M. (2015). The mind of the male batterer: a neuroscience perspective. Aggression and Violent Behavior, 25, 243251. https://doi.org/10.1016/j.avb.2015.09.009

Campbell, J. C., Anderson, J. C., McFadgion, A., Gill, J., Zink, E., Patch, M., Callwood, G., \& Campbell, D. (2018). The effects of intimate partner violence and probable traumatic brain injury on central nervous system symptoms. Journal Women's Health, 27(6), 761-767. https://doi.org/10.1089/jwh.2016.6311

Chamaz, K. (2014) Constructing Grounded Theory ( $2^{\text {nd }}$ ed) Thousand Oaks, CA:Sage.
Cody, M. W., Jones, J. M., Woodward, M. J., Simmons, C. A., \& Beck, G. J. (2015). Correspondence between self-report measures and clinician assessments of psychopathology in female intimate partner violence survivors. Journal Interpersonal Violence, 32(10), 1501-1523. https://doi.org/10.1177/0886260515589566

Colantonio, A., Kim, H., Allen, S., Asbridge, M., Petgrave, J., \& Brochu, S. (2014). Traumatic brain injury and early life experiences among men and women in a prison population. Journal of Correctional Health Care, 20(4), 271-279. https://doi.org/10.1177/ 1078345814541529

Corrigan, J. D., \& Deutschle, J. J. (2008). The presence and impact of traumatic brain injury among clients in treatment for cooccurring mental illness and substance abuse. Brain Injury, 22(3), 223-231. https://doi.org/10.1080/02699050801938967

Crane, C., \& Easton, C. (2017). Physical health conditions and intimate partner violence perpetration among offenders with alcohol use diagnoses. Journal of Interpersonal Violence, 32(11), 1678-1691. https://doi.org/10.1177/0886260515590124

Craparo, G., Gori, A., Petruccelli, I., Cannella, V., \& Simonelli, C. (2014). Intimate partner violence: relationships between alexithymia, depression, attachment styles, and coping strategies of battered women. Journal Sexual Medicine, 11(6), 1484-1494. https://doi.org/10.1111/jsm.12505

Currie, J. \& Tekin, E. (2006). Does Child Abuse Cause Crime? (Discussion Paper No. 2063). Bonn, Germany: The Institute for the Study of Labor. http://ftp.iza.org/dp2063.pdf.

Cutajar, M., Ogloff, J. \& Mullen, P. (2011). Child sexual abuse and subsequent offending and victimisation: a 45-year follow-up study. Australia: Criminology Research Council. https://aic.gov. au/publications/tandi/tandi440. Accessed 10 June 2020.

Durand, E., Chevignard, M., Ruet, A., Dereix, A., Jourdan, C., \& Pradat-Diehl, P. (2017). History of traumatic brain injury in prison populations: a systematic review. Annals of physical and rehabilitation medicine, 60, 95-101. https://doi.org/10.1016/j.rehab. 2017.02.003

Donkelaar, P.V. (2018) "Traumatic brain injury: The unseen impact of domestic violence". The Conversation. 17 April. https://theco nversation.com/traumatic-brain-injury-the-unseen-impact-ofdomestic-violence-92730. Accessed 28 May 2020

Doyle, M., Shaw, J., Carter, S., \& Dolan, M. (2010). Investigating the Validity of the Classification of Violence Risk in a UK Sample. International Journal of Forensic Mental Health, 9(4), 316-323. https://doi.org/10.1080/14999013.2010.527428

Easton, C., Sacco, K., Neavins, T., Wupperman, P., \& George, T. (2008). Neurocognitive performance among alcohol dependent men with and without physical violence toward their partners: a preliminary report. The American Journal of Drug and Alcohol Abuse, 34(1), 29-37. https://doi.org/10.1080/009529907017643 26

Eriksson, A., Saunders, B., Lansdell, G., \& Bunn, R. (2019). Short fuse and no filter: Acquired Brain Injury - How a medical disability transforms into a social and criminal justice concern. International Journal of Law, Crime and Justice, 57, 126-136. https://doi.org/10.1016/j.ijlcj.2019.03.008.

Farrer, T., Frost, R., \& Hedges, D. (2012). Prevalence of traumatic brain injury in intimate partner violence offenders compared to the general population: a meta-analysis. Trauma, Violence \& Abuse, 13(2), 77-82. https://doi.org/10.1177/1524838012440338

Felitti, V. J., Anda, R. F., Nordenberg, D., Williamson, D. F., Spitz, A. M., Edwards, V., et al. (1998). Relationship of childhood abuse and household dysfunction to many of the leading causes of death in adults: The Adverse Childhood Experiences (ACE) Study. American Journal of Preventive Medicine, 14(4), 245-258. https://doi.org/10.1016/S0749-3797(98)00017-8

Fernández-Serrano, M., Pérez-García, M., \& Verdejo-García, A. (2011). What are the specific vs. generalized effects of drugs 
of abuse on neuropsychological performance?. Neuroscience \& Biobehavioral Reviews, 35(3), 377-406. https://doi.org/10.1016/j. neubiorev.2010.04.008.

Goss, J. D., Leinbach, T. R. (1996). Focus groups as alternative research practice. Area, 28(2), 115-23

Gould, K. R., Ponsford, J. L., Johnston, L., \& Schonberger, M. (2011). The nature, frequency and course of psychiatric disorders in the first year after traumatic brain injury: A prospective study. Psychological Medicine, 41(10), 2099-2109. https://doi.org/10.1017/ s003329171100033x

Gould, K., Hicks, A., Hopwood, M., Kenardy, J., Krivonos, I., Warren, N., \& Ponsford, J. (2017). The lived experience of behaviours of concern: a qualitative study of men with traumatic brain injury. Neuropsychological rehabilitation, 29(3), 376-394. https://doi. org/10.1080/09602011.2017.1307767

Guinn, A., Ports, K., Ford, D., Breiding, M., Merrick, M. T., (2019) Associations between adverse childhood experiences and acquired brain injury, including traumatic brain injuries, among adults: 2014 BRFSS North Carolina, Injury Prevention, 25, 514-520. https://doi.org/10.1136/injuryprev-2018-042927

Holloway, M. (2014). How is ABI assessed and responded to in nonspecialist settings? Is specialist education required for all social care professionals? Social Care and Neurodisability, 5(4), 201213. https://doi.org/10.1108/SCN-12-2013-0043

Hughes, N., Williams, H., Chitsabesan, P., Davies, R., \& Mounce, L. (2012). Nobody made the connection: the prevalence of neurodisability in young people who offend. London: Office of the Children"s Commissioner. https://www.childrenscommissioner. gov.uk/wp-content/uploads/2017/07/Nobody-made-the-conne ction.pdf Accessed 2 April 2020.

Hunnicutt, G., Lundgren, K., Murray, C., \& Olson, L. (2017). The intersection of intimate partner violence and traumatic brain injury: a call for interdisciplinary research. Journal of Family Violence, 32, 471-480. https://doi.org/10.1007/s10896-016-9854-7

Iverson, K. M., Dardis, C. M., \& Pogoda, T. K. (2017). Traumatic brain injury and PTSD symptoms as a consequence of intimate partner violence. Comprehensive Psychiatry, 74, 80-87. https://doi.org/10. 1016/j.comppsych.2017.01.007

Iverson, K. M., Dardis, C. M., Grillo, A. R., Galovski, T. E., \& Pogoda, T. K. (2019). Associations between traumatic brain injury from intimate partner violence and future psychosocial health risks in women. Comprehensive Psychiatry, 92, 13-21. https://doi.org/10. 1016/j.comppsych.2019.05.001

Jackson, H., Philp, E., Nuttall, R. L., \& Diller, L. (2002). Traumatic brain injury: a hidden consequence for battered women. Professional Psychology: Research and Practice, 33(1), 39-45

Kalmakis, K., \& Chandler, G. (2014). Adverse childhood experiences: Towards a clear conceptual meaning. Journal of Advanced Nursing, 70, 1489-1501.

Kitzinger, J. (1995). Introducing focus groups. British Medical Journal, 311, 299-302. https://doi.org/10.1136/bmj.311.7000.299

Kwako, L., Glass, N., Campbell, J., Melvin, K., Barr, T., \& Gill, J. (2011). Traumatic brain injury in intimate partner violence: a critical review of outcomes and mechanisms. Trauma, Violence \& Abuse, 12(3), 115-126. https://doi.org/10.1177/1524838011 404251

Lansdell, G., Saunders, B., Eriksson, A., Bunn, R., \& Baidawi, S. (2018a). Enhancing the rights and well-being of people with acquired brain injuries in the criminal justice system: Some findings from a qualitative study. Australian Journal of Social Issues, 53(2), 88-106. https://doi.org/10.1002/ajs4.41.

Lansdell, G., Saunders, B., Eriksson, A., Bunn, R., \& Baidawi, S. (2018b). I'm not drunk, I have an ABI: Findings from a qualitative study into systematic changes in responding to people with acquired brain injuries in the justice system. Psychiatry, Psychology and Law, 25(5), 737-758. https://doi.org/10.1080/13218719.2018. 1474818 .

Lifshitz, J., Crabtree-Nelson, S., \& Kozlowski, D. (2019). Traumatic Brain Injury in Victims of Domestic Violence. Journal of Aggression, Maltreatment and Trauma, 28(6), 655-659. https://doi.org/ 10.1080/10926771.2019.1644693

McHugo, J., Krassenbaum, D., Donley, E., Corrigan, E., Bogner, E., \& Drake, E. (2017). The prevalence of traumatic brain injury among people with co-occurring mental health and substance use disorders. Journal of Head Trauma Rehabilitation, 32(3), E65-E74. https://doi.org/10.1097/htr.0000000000000249

McKinlay, A., Corrigan, J., Horwood, J., \& Ferguson, D. (2014). Substance abuse and criminal activities following traumatic brain injury in childhood, adolescence, and early adulthood. Journal of Head Trauma Rehabilitation, 29(6), 498-506. https://doi.org/10. 1097/htr.0000000000000001

McMillan, T. M., Wood, R. L., \& 1. (Eds.). (2017). Neurobehavioural disability and social handicap following traumatic brain injury. (2nd ed.). Taylor \& Francis.

Maher, JM., Spivakosky, C., McCulloch, J., McGowan, J., Beavis, K., Lea, M., Cadwallader, J., \& Sands, T. (2018). Women, disability and violence: Barriers to accessing justice: Final Report (Research Report, ANROWS Horizons: Issue02/2018). Sydney: ANROWS.

Monahan, K. (2018). Commentary: intimate partner violence, traumatic brain injury, and social work: moving forward. Social Work, 63(2), 179-181. https://doi.org/10.1093/sw/swy005

Monahan, K., \& O'Leary, K. D. (1999). Head injury and battered women: an initial inquiry. Health \& Social Work, 24, 269-278. https://doi.org/10.1093/hsw/24.4.269

Monahan, J. (2010). The Classification of Violence Risk. In R. K. Otto \& K. S. Douglas (Eds.), International perspectives on forensic mental health. Handbook of violence risk assessment. New York: Routledge.

Moore, E., \& Haysom, L. (2014). Traumatic brain injury, mental health, substance use, and offending among incarcerated young people. Journal of Head Trauma Rehabilitation, 29(3), 239-247. https://doi.org/10.1097/htr.0b013e31828f9876

Murray, C. E., Lundgren, K., Olson, L. N., \& Hunnicutt, G. (2016). Practice update what professionals who are not brain injury specialists need to know about intimate partner violence related traumatic brain injury. Trauma, Violence, \& Abuse, 17(3), 298-305

Nemeth, J. M., Mengo, C., Kulow, E., Brown, A., \& Ramirez, R. (2019). Provider perceptions and domestic violence (DV) survivor experiences of traumatic and anoxic-hypoxic brain injury: Implications for DV advocacy service provision. Journal of Aggression, Maltreatment and Trauma, 28(6), 744-763. https://doi.org/ 10.1080/10926771.2019.1591562

O'Rourke, C., Linden, M. A., \& Lohan, M. (2017). Misconceptions about traumatic brain injury among probation services. Disability and Rehabilitation, 40(10), 1119-1126. https://doi.org/10.1080/ 09638288.2017 .1288274$.

Pinto, L., Sullivan, E., Rosenbaum, A., Wyngarden, N., Umhau, J., Miller, M., \& Taft, C. (2010). Biological correlates of intimate partner violence prevention. Aggression and Violent Behaviour, 15, 387-398. https://doi.org/10.1016/j.avb.2010.07.001

Prince, C., \& Bruhns, M. (2017). Evaluation and treatment of mild traumatic brain injury: The role of neuropsychology. Brain Sciences, 7(12), 105. https://doi.org/10.3390/brainsci7080105

Rosenbaum, A., \& Hoge, S. K. (1989). Head injury and marital aggression. The American Journal of Psychiatry, 146(8), 1048-1051

Rushworth, N. (2011). Out of sight, out of mind: people with an acquired brain injury and the criminal criminal justice system. Brain Injury Australia.

Schneider, V. (2010). Submission to the Productivity Commission's inquiry into disability care and support. Brain Injury Australia. 
Shiroma, E. J., Ferguson, P. L., \& Pickelsimer, E. E. (2010). Prevalence of traumatic brain injury in an offender population: A meta-analysis. Journal of Correctional Health Care, 16(2), 147-159. https://doi. org/10.1177/1078345809356538

Smirl, J. D., Jones, E. K., Copeland, P., Khatra, O., Taylor, E. H., \& Donkelaaron, P. V. (2019). Characterizing symptoms of traumatic brain injury in survivors of intimate partner violence. Brain Injury, 33(12), 1529-1538. https://doi.org/10.1080/02699052. 2019.1658129

Sprague, J., Verona, E., Kalkhoff, W., \& Kilmer, A. (2011). Moderators and mediators of the stress-aggression relationship: executive function and state anger. Emotion, 11(1), 61-73. https://doi.org/ $10.1037 / \mathrm{a} 0021788$

St. Ivany, A., \& Schminkey, D. (2016). Intimate partner violence and traumatic brain injury. Family and Community Health, 39(2), 129-137. https://doi.org/10.1097/fch.0000000000000094.

St. Ivany, A., \& Schminkey, D. (2019). Rethinking traumatic brain injury from intimate partner violence: A theoretical model of the cycle of transmission. Journal of Aggression, Maltreatment, and Trauma, 28(7), 785-806. https://doi.org/10.1080/10926771.2019. 1632400.

St. Ivany, A., Bullock, L., Schminkey, D., Wells, K., Shaprs, P., \& Kools, S. (2018). Living in Fear and Prioritizing Safety: Exploring Women's Lives After Traumatic Brain Injury From Intimate Partner Violence. Qualitative Health Research., 28(11), 1708-1718. https://doi.org/10.1177/1049732318786705.

State of Victoria. (2016). Royal Commission into Family Violence: summary and recommendations (Parliamentary Paper, No 132). Victorian Government.

Stephens, A., Cullen, J., Massey, L., \& Bohanna, I. (2014). Will the National Disability Insurance Scheme Improve the Lives of those Most in Need? Effective Service Delivery for People with Acquired Brain Injury and other Disabilities in Remote Aboriginal and Torres Straight Islander Communities. Australian Journal of Public Administration, 73(2), 260-270. https://doi.org/10.1111/ 1467-8500.12073

Stern, J. (2004). Traumatic brain injury: an effect and cause of domestic violence and child abuse. Current Neurology and Neuroscience Reports, 4(3), 179-181. https://doi.org/10.1007/ s11910-004-0034-4
Synapse. (2016). Acquired brain injury: the facts. https://synapse.org. au/media/143849/2016_abi_the_facts_digital.pdf Accessed 26 May 2020.

Taliaferro, E., Mills, T., Walker, S. (2001) Walking and Talking victims of strangulation. Is there a new epidemic? A commentary. Journal of Emergency Medicine, 21(3), 293-295. https://doi.org/10.1016/ s0736-4679(01)00397-3.

Valera, E. (2018). Editorial: Increasing our understanding of an overlooked public health epidemic: traumatic brain injuries in women subjected to intimate partner violence. Journal of Women's Health, 27(6), 735-736. https://doi.org/10.1089/jwh.2017.6838

Valera, E. M., \& Berenbaum, H. (2003). Brain injury in battered women. Journal of Consulting Clinical Psychology., 71(4), 797804. https://doi.org/10.1037/0022-006X.71.4.797.

Valera, E., \& Kucyi, A. (2017). Brain injury in women experiencing intimate partner-violence: neural mechanistic evidence of an "invisible" trauma. Brain Imaging Behaviour, 11(6), 1664-1677. https://doi.org/10.1007/s11682-016-9643-1

World Health Organization. (2012). Understanding and addressing violence against women. https://www.who.int/reproductivehealth/topics/ violence/vaw_series/en/ Accessed 14 January 2020.

Williams, H. (2012). Repairing shattered lives: brain injury and its implications for criminal justice. Exeter, UK: Centre for Clinical Neuropsychology Research, University of Exeter. https://www. barrowcadbury.org.uk/wp-content/uploads/2012/11/RepairingShattered-Lives_Report.pdf. Accessed 23 May 2020.

Wong, J., Fong, D., Lai, V., \& Tiwari, A. (2014). Bridging intimate partner violence and the human brain: a literature review. Trauma, Violence \& Abuse, 15(1), 22-33. https://doi.org/10. $1177 / 1524838013496333$

Zieman, G., Bridwell, A., \& Cardenas, J. (2017). Traumatic brain injury in domestic violence victims: a retrospective study at the Barrow Neurological Institute. Journal of Neurotrauma, 34(4), 876-880. https://doi.org/10.1089/neu.2016.4579

Publisher's Note Springer Nature remains neutral with regard to jurisdictional claims in published maps and institutional affiliations. 